Hagar Kotef and

Merav Amir

\title{
(En)Gendering Checkpoints: Checkpoint Watch and the Repercussions of Intervention
}

\begin{abstract}
his article is the outcome of three years of experience, between the two of us, of weekly shifts, standing with Checkpoint Watch (CPW) at the checkpoints that are spread throughout the Palestinian Occupied Territories. It is the product of these three years of observations, dilemmas, internal conflicts, and contradictory impulses. All of the critiques that this article suggests are thus ones that we as members of CPW often struggled with ourselves. They are by no means an attempt to undermine CPW and the important work it does. To the contrary, we both think CPW is one of the most significant and effective organizations operating today against the Israeli occupation. This article is dedicated to this organization and, in particular, to the remarkable and rare women with whom we have the privilege to stand, week after week, protesting against the occupation.
\end{abstract}

\section{Introduction}

All of a sudden one of the soldiers cracks. . . . He decides to close down the checkpoint, not letting anyone through. We [the activists] tried to call anyone who might assist . . . to no avail; left messages but got no response. . . . It is a cold and rainy day, and it's getting dark. . . . [Suddenly,] one old lady . . . decides that she has had enough. She bypasses the lines and the checkpoint, and simply starts walking home. The soldiers are after her, shouting. . . . She shouts that she cannot bear it any longer and refuses to go back in line. The soldiers panic in light of this "rebellion," and their reaction is a collective punishment: the line for the

We would like to thank Wendy Brown, Amir Engel, Hanna Freund-Chertok, Keren Sadan, Yves Winter, and Effi Ziv for reading different versions of this article and for providing us with many enlightening comments and Adi Ophir for providing the conceptual framework through which we think.

[Signs: Journal of Women in Culture and Society 2007, vol. 32, no. 4]

(c) 2007 by The University of Chicago. All rights reserved. 0097-9740/2007/3204-0005 $\$ 10.00$ 
elderly is closed. Whoever was standing in this line must go back and stand in one of the other lines. But they refuse. They have been standing there too long to start all over again. In the meantime, the soldiers let almost no one through. . . . The lines are getting longer and longer, and the pressure is intolerable. The women start crying. They have a home, they say, they want to go home.

—Checkpoint Watch report, Beit Iba, January 31, 2005 (translation ours $)^{1}$

Beit Iba, the checkpoint depicted in this report, is located at the outskirts of Nablus, one of the major Palestinian cities in the West Bank. The Palestinian Occupied Territories are paved with hundreds of such checkpoints; some are manned checkpoints, others are roadblocks, metal gates, and earth mounds. ${ }^{2}$ The checkpoints, which create a dense grid of limitations upon the movement of Palestinians, fragmenting both the space and its population, have become one of the most predominant technologies of the occupation since the 1993 Oslo Accords. Most of these checkpoints are not located between "Israel" and "Palestine" but inside the Palestinian territories: on the entrance roads to villages, preventing all vehicles from entering or leaving them; enclosing the cities, separating them from the surrounding towns and villages that depend on them; and fracturing the few roads on which the Palestinians are allowed to move. They prevent any real possibility of maintaining normal daily lives (getting to work, school, the doctor, the market) and of establishing a viable political existence of an independent Palestinian entity (maintaining a political community and territorial continuity). ${ }^{3}$

Checkpoint Watch (Machsom Watch in Hebrew) was founded in 2001 by a small group of women who became aware of the expansion and growing significance of the checkpoints in the ongoing occupation. It is

${ }^{1}$ See http://www.machsomwatch.org/reports/viewReport.asp?step $=3 \&$ reportId $=7545$ \&link $=$ viewReport\&lang $=$ heb

${ }^{2}$ In January 2006 there were 471 physical obstacles placed by the Israeli army on roads throughout the Occupied Territories (UN Office for the Coordination of Humanitarian Affairs 2006). While the term checkpoint often serves as a generic term describing all types of movement-restricting obstacles, CPW activity focuses on checkpoints that are manned by army personnel, through which both vehicles and pedestrians must pass. Currently there are approximately fifty manned checkpoints throughout the West Bank.

${ }^{3}$ For a detailed account of the checkpoints and their history, see Keshet (2006) and Hass (2006). Said Zeedani (2005) provides a Palestinian perspective on the implications of the checkpoint on Palestinian life. Updated information can be found at the Checkpoint Watch Web site (http://www.machsomwatch.org) and at the B'Tselem Web site (http:// www.btselem.org). 
an all-women Israeli organization, currently including about four hundred volunteers, who stand in small groups of two to five women, in two shifts, morning and evening, at more than forty checkpoints (the main, manned checkpoints throughout the West Bank). The main goal of Checkpoint Watch is to protest against the occupation and in particular against the checkpoints. In a manner similar to that of other watch organizations, the primary practices chosen for that purpose are the regular presence of the activists at the checkpoints, observation, and documentation. The reports, written after every shift, are published on the organization's Web site and are sometimes sent to Israeli and international media, members of parliament, or high-ranking officers in the Israeli army. Later on, forms of intervention were also adopted by the members. These interventions include a wide variety of practices in accordance with each member's disposition and convictions. They range from serving as a physical buffer between violent soldiers and Palestinians, to persuading soldiers to show more consideration to the Palestinians (such as allowing ill individuals hospital visits even when they do not have all the necessary permits), to advocating for rules and regulation changes. These intervening practices were an outcome of growing frustration and a sense of helplessness, as well as the almost instinctive desire to do something, anything, about the distress the activists encounter.

But what does it mean to "do something" in this context? In what follows we will depict some of the more vexing effects of the doings of CPW. To this end, we will trace the body, and in particular the gendered body, within the reality of the checkpoints. Drawing primarily from the conceptual frameworks of Michel Foucault and Judith Butler, we will show that in the case of CPW efficacy is rooted in gender: the bodily presence of the activists at the checkpoints, which is the foundation of the organization's activity, is highly gendered. Gender first creates a breach through which CPW activists can access the checkpoints (the activists gain access to these military zones because they are female) and then materializes into a corporeal excess in the activists' activity. Corporeal excess, we argue, is a function of two factors. The first is the seizing of one corporeal axis over others: if a body is a compound matrix, comprised of multiple axes (such as sexuality, reproduction, skin color, size, vulnerability, and so forth), a corporeal excess is produced when one of these axes gains disproportionate dominance over the others. Second, excess is a function of the context in which this seizing is made: it is produced when a particular bodily axis consolidates and emerges within a temporal and spatial field in forms and density that do not comply with a given norm (a norm that is often constructed particularly to constitute this corporeal presence 
as excessive). Therefore excessiveness, solidified through these two factors, is a historical and social attribute. It is embedded in the normative grids that are at work in particular situations and in the constructions of group identities. (Hence, for example, a heteronormative society, environment, or particular situation would render any presence of same-sex sexual behavior as dominating any other aspect, and thus as "excessive," while the same practices performed in a heterosexual manner would be perceived as coexisting with other dimensions and thus "balanced.") Checkpoints are spatial zones producing, or at least accompanied by, several types of bodily excess: the excess of the bodies of Israelis, whose precarious lives provide the substrate for the ideology that justifies the checkpoints; that of the soldiers' bodies, both in their eruptive violence (from the Palestinian and leftist perspectives) and their vulnerability to Palestinian violence (from the army's perspective); and that of the two types of bodies that are at the focus of this article-those of the Palestinians and those of CPW

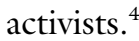

The following section attempts to show how Palestinians' bodies function in Israeli mainstream discourses in ways that enable the establishment and sustainment of the checkpoints and how the bodily distresses induced by these sites trigger the pressing need of CPW activists to be effective. ${ }^{5}$ The subsequent section analyzes the gendered corporeal excess of CPW women. As CPW is an all-women organization, and for other reasons that this article explores, the forms of intervention of CPW assume gendered traits. Thereby another front is added to the activity of CPW: it is not only a peace organization, challenging nationalism and militarism, but also a feminist organization, operating against sexism. These gendered aspects not only add another axis of analysis, another factor to the ideological and political fronts in which this organization operates but also create a complex matrix in which considerations and countereffects of these two fronts blend into, contradict, and interfere with each other. ${ }^{6}$

\footnotetext{
${ }^{4}$ We borrow the expression "precarious life" from Butler (2004). Although our arguments here diverge from her analysis, we would still like to preserve her comprehension of the political and ethical significance of such a precariousness.

${ }^{5}$ Because this article is about an Israeli nongovernmental organization (NGO) and Israeli rule in the Occupied Territories, we refer to Palestinians predominantly from an Israeli perspective. Consequently, and almost unavoidably, this article duplicates the problematic objectification of the Palestinians made in these discourses.

${ }^{6}$ As Anne McClintock suggests, "Race, gender and class are not distinct realms of experience, existing in splendid isolation from each other; nor can they be simply yoked together retrospectively like armatures of Lego. Rather, they come into existence in and through relations to each other-if in contradictory and conflictual ways" (McClintock 1995, 5).
} 
One should therefore take into account the complexities created by the conjunction of these two fronts and aim to map out the effects, profits, and costs of this superimposition.

\section{Suffering, violence, and rudimentary life: Bodies of Palestinians}

On August 26, 2003, twenty-nine-year-old Rula Astia delivered a baby at the Beit Furik checkpoint, on the eastern outskirts of Nablus. Rula and her husband, Da'ud, live in a village ten minutes drive from Nablus, were it not for the checkpoint. Rula was eight months pregnant when she started getting contractions. She recalls: "We took a taxi and got off a fair distance from the checkpoint, since cars are not allowed to reach the checkpoint itself. From there we walked the rest of the way. I was in pain. There were a few soldiers at the checkpoint; they . . . ignored us. Da'ud went to speak to them, and one of them pointed his gun at him. . . . I was in pain and felt that I was going to deliver the baby there. . . . I laid down on the ground, in the dirt, and crawled behind a concrete block to get some privacy, and there I had the baby, in the dirt, like an animal. I held the baby, she moved a little, but a few minutes later she died in my arms." Da'ud continues: "After she had the baby Rula was crying, and then she screamed that the baby has died. She was crying, I was crying. . . . She held the baby in her arms, covered with blood, the umbilical cord was lying in the dirt, still connected, I had to cut it with a rock; I didn't have anything else I could use. Then I picked Rula up in my arms and carried her across the checkpoint to the ambulance, while she was holding our dead baby."

-Amnesty International 2005, 7 (translation ours)

The singularity of a story creates a breach. Here, the story of the Astia family allows a segment of the actual experience of Palestinians at the checkpoints to penetrate into this article. Yet here we would like to trace how this singularity is dissolved, becomes a form, a figure, a pattern, and how the form of suffering and more specifically the figures of suffering bodies function.

Bodies of Palestinians are the addressees of a wide spectrum of activities, techniques, and tactics deployed by CPW. These activities, techniques, and tactics consist of different ways of addressing not only the extreme cases, such as the one above, or cases of brute violence, but also the mundane dimensions of human existence in the body-needing shelter from the blazing sun in summer and from the rain in winter and basic facilities for water and toilets. We argue that, on the whole, these acts can 
be understood as at one and the same time humanitarian actions addressing human suffering and actions subverting the Israeli discourse of national security. We start with the latter.

Palestinian bodies not only inhabit the checkpoints, they also populate mainstream Israeli discourse regarding the occupation at large and the checkpoints in particular. Two main types of bodies, two main figures, constitute this discourse: the explosive body of the terrorist and the woman giving birth at the checkpoint. While the body of the suicide terrorist is the major inhabitant of the discourse of national security, the laboring woman has become an emblem in leftist Israeli discourse of the injustice of the checkpoints. Despite the daily routine of injustice at the checkpoints, she has become the symbol of all wrongs inflicted upon the innocent Palestinians. This iconization is both an outcome and a technique of the feminization of Palestinian suffering. It goes hand in hand with the mirrored masculinization of the Palestinian body that inflicts suffering (upon the Israelis), which produces the second type of body: the explosive body. The body that explodes in suicide attacks is always masculinized, even when the attack is performed by a woman. ${ }^{7}$ This allows mainstream Israeli discourse to create a split in Palestinian existence, a split between victims and perpetrators, between those who arouse compassion and those who generate fear. While this is a reconstruction of the worn-out gender division of labor, in which passive suffering is feminized and active agency producing violence is masculinized, here it carries broader political significance. This gendered split is one of the factors that enable the production and sustainment of the schizoid Israeli mentalité that gives rise to the notion of "enlightened occupation." It breaks the causal link between suffering and terror, separating and molding them into the seemingly clean and well-defined masculine/feminine dichotomy. It is because of this operation that the superimposition of humanitarian discourse onto the reality of occupation is sustainable.

Indeed, at the level of mainstream Israeli discourse, Palestinians have a double corporeal excess that is created in tandem with a gender demarcation. It is an excess constructed by a combination of the two factors introduced above: first, it is a function of an aberrant dominance of one

7 This is perhaps why female suicide bombers create such perplexity. See, e.g., Naaman 2007.

8 The term enlightened occupation reflects the belief that the Israeli occupation can be administered legally, humanely, and considerately and that the occupation actually benefits the Palestinians by giving them better life conditions than they would otherwise have had. This notion prevailed in Israel at least until the first intifada (1987), and there are still traces of it in mainstream discourses. 
axis of embodiment, in this case the axes of reproduction and volatility. Second, it is marked as excess because of the seemingly inappropriate appearance of this axis-giving birth in a war zone and exploding in civilian surroundings. However, at the checkpoint itself this gendered dichotomy collapses and is replaced by two nongendered superfluities: from the perspective of the army, the gender distinction collapses into the axis of explosiveness; from that of $\mathrm{CPW}$ activists it collapses into the axis of vulnerability. We begin with the former.

The logic and the grammar of the checkpoints reduce all Palestinians to perilous corporeality. Accordingly, even when a pregnant woman arrives at the checkpoint, she may be denied passage or taken aside to undergo a thorough body inspection to verify that her abdomen is not in fact an explosive belt. As bodies that can explode at any moment and thereby terminate themselves as they terminate others, Palestinians embody death. Moreover, passing daily in front of loaded rifles whose use is not restrained by any law, theirs is a life whose potential end is acutely present at any moment. This state of in-betweenness, of bodies positioned on the threshold of death, is intensified by an additional factor. Palestinian lives are managed as lives whose actuality has been reduced to the minimal sustainment of existence and as such stripped of what is considered normal and full. ${ }^{9}$ This form of existence is interlocked with the occupation itself; it is insuperable from its specific form of rule. Checkpoint Watch aims to counter this construction of the Palestinians at the checkpoints by insisting on the mundane aspects of their existence. By demanding that the young man who is detained by the soldiers, presumably for security reasons, be allowed to sit down, drink, or urinate, the group reconstitutes the Palestinian body within Israeli security-oriented discourse as a live body, in contrast to the mere exploding body that is usually present there. ${ }^{10} \mathrm{By}$ bringing forth an alternative narrative in which the Palestinian body is fully alive and therefore should be attributed with mundane needs and

\footnotetext{
${ }^{9}$ Herein we only briefly touch on the question of what can be counted as human (or full) life and how the inclusion and exclusion of some lives from the domain of humanity play a part in a normative-many times oppressive - construction of lives. For a more complete account, see Butler (2004).

${ }^{10}$ It is important for us to emphasize that this constitution is an intra-Israeli matter. By no means do we claim here that Palestinians are dependent upon the Israeli grid of meanings in order to construct their own identities. However, within colonial contexts one cannot fully separate the identity of the colonized from his or her construction in the eye of the colonizer (Fanon 1967). This is especially true since the Israeli construction of the Palestinian as an explosive body is what enables the persistence of the Israeli forms of rule in the Occupied Territories in general and the checkpoint system in particular.
} 
allowed to sustain its dignity, CPW opposes not just the construction of the Palestinian as a body on the threshold of death but also the derivative of this liminal positioning, the very discursive conditions that facilitate the forms of rule over the Palestinians.

Yet CPW strives to counter not only the security-oriented discourse but also the complementary iconized construction of Palestinian suffering in mainstream Israeli discourse and its tendency to focus on exceptional and extreme cases by drawing attention precisely to the ongoing and regular hardships inflicted upon Palestinians at the checkpoints. This attempt to resist the iconization of suffering is not just the intention and rhetoric of CPW; it is also the modus operandi of this type of activism: the somewhat Sisyphean character of the activity; the regular, daily shifts (most CPW activists go out once a week, every week, to the same checkpoints); the regular, daily reports (written every day, for each shift, even when nothing out of the ordinary occurs). These reports often look the same: counting the cars waiting to pass; measuring the time it takes one person to go through the checkpoint; the repetitive, almost cyclic encounter with the checkpoints-the same distress, the same routine violation of basic human rights, the same frustrating responses from the army. These forms of operation mirror the suffering they wish to display: a daily, lasting, ongoing suffering that cannot be iconized. By bringing to light the multiple forms of violence that the checkpoints produce, or more accurately the violence that resides in the mere existence of the checkpoints, they undermine the iconization of the woman in labor as a figure that embodies the surplus violence of the checkpoints. When it cannot be constructed as a surplus, this violence can no longer be portrayed as a mere byproduct of the occupation that may therefore be contained.

As suggested above, addressing corporeal suffering can also be understood within the framework of humanitarian intervention. Much has been written about the double edge of humanitarian work, and many of the critiques analyzing the complex implications that this type of work carries are applicable to CPW: the enfeeblement of the voice of the local population, the collaboration with the oppressive authorities, and providing the conditions of possibility for the atrocious situation. ${ }^{11}$ Drawing from

${ }^{11}$ Most critiques of humanitarianism tie these aspects together. Alex De Waal (1997) and John Prendergast (1996) show how these three aspects are interwoven in the case of humanitarian NGOs in Africa. Ariella Azoulay and Adi Ophir (2004) and Rema Hammami (2000) analyze NGOs operating in the Palestinian Occupied Territories. They provide accounts of the complex relations of these organizations with local authorities (Israeli as well as Palestinian) and their role in the perpetuation of the occupation. 
this critique, the following analysis examines the humanitarian aspects of CPW's intervention and suggests that additional processes are at play in this case. This examination also provides the framework that the genderoriented analysis of the next section echoes.

It might seem that expressions such as "elderly people," "women and children," "crying babies," and "the sick" in reference to Palestinians at the checkpoints have become well-worn figures of speech in the discourse of the critical Left. However, arriving at the checkpoints, CPW activists could not overlook the actual and immediate suffering of the Palestinians there, the pressure and crowdedness in which they stand, exposed to the elements, sometimes for hours, and the long, muddy pathways through which they have to walk in order to cross the checkpoint. Activists saw that the sick and the elderly had nowhere to sit while they waited and that men detained for long hours were humiliated by having to relieve themselves in open fields, in full view of others standing in line, since there were no toilets available for them.

Although the principal aims of CPW activists are to protest the existence of the checkpoints and to document what they see there, the encounters with these conditions produced in most CPW activists an urge to alleviate some of the distress they were witnessing. They started by doing what they could: they carried bottles of water in their backpacks in order to supply water to people detained at the checkpoint for long periods of time. However, since CPW is not a humanitarian organization at its core, it lacks the resources and expertise to provide adequate solutions to the immediate bodily distresses at the checkpoints. Moreover, since it does not wish to aid the Israeli authorities in relinquishing their responsibility for the dire circumstances they have created, CPW started demanding that the army supply the basic necessary facilities. First, the organization demanded that the army supply water to any Palestinian, then it insisted that toilet facilities be installed and that shading be constructed in order to protect the people from the Middle Eastern sun in summer and the cold winter rain.

Reluctantly and slowly, the army complied: shadings were erected and toilets installed. Consequently, the checkpoints became entrenched: what started as a cement cube on a dirt path, behind which the soldiers stood, was expanded, developed, and solidified, evolving from a provisory obstacle into a permanent and elaborate construction. At some of the bigger checkpoints a trailer containing diapering posts and first-aid facilities appeared carrying a sign: "humanitarian post." And so, amid a site where suffering is inflicted as a matter of routine and whose mere existence is a violation of human rights, a post suddenly emerges, a post where, so the 
sign declares, human needs are attended to and human dignity is maintained, perhaps even restored. It may be obvious that we have never witnessed any mother diapering her baby in this trailer or any Palestinian receiving any medical treatment. The absurdity and emptiness of this post is manifested in the fact that for weeks this trailer stood locked. No soldier, and certainly no Palestinian, knew what it contained or what it was for. Yet the fact that these big trailers, which increase the spatial presence of the checkpoints, are called humanitarian posts shows how, in the process of swelling - partly as a result of ingesting humanitarian demands - the checkpoints also swallowed humanitarian language. And so an emphasis given to a corporeal excess of the Palestinians that materializes through the pivot of suffering induces the pervasiveness of the corporeality of the checkpoint itself: the shadings, trailers, roads, water tanks, and toilet facilities. Obviously, CPW was not the sole contributor to this process; the powers of occupation have their own agenda and internal dynamics. Yet being an organization that is dedicated to annulling the checkpoints, CPW's contribution-minor as it is-is particularly vexing.

Toward the end of 2005, a new form of elaborated checkpoint appeared: "the terminal." Unlike the other checkpoints, terminals are built through and through. Surrounded by concrete walls, roofed, and containing clearly marked designated areas (such as a "waiting area" or gates for people in wheelchairs), they are erected as architectural monstrosities. These constructions are equipped with an array of monitoring and control apparatuses-from electric iron turnstiles to security cameras and biometric identification devices-that enable the soldiers to control the checkpoints from an isolated edifice. Despite their title, most of them are located, like most checkpoints, inside Palestinian territory. They are built like border crossings, reinforcing the illusion that they are normal sites marking the border between two sovereign entities and concealing the fact that Israeli rule applies on both sides of the terminal. With seemingly friendly welcome signs, vast parking lots (in which no one parks-the Palestinians have no access by car to the checkpoint area), benches (on which no one sits), toilets (which are often out of order), the terminals present a facade of legitimacy. In a grotesque way, these checkpoints are everything that $\mathrm{CPW}$ women, in their humanitarian cast, could have hoped for. If what the CPW activists saw at the checkpoints was corporeal suffering, corporeal suffering has been attended to by the army-so much so that no words were left to describe the monstrosity of these new checkpoints. Reading reports written by CPW members from these checkpoints, one could see the struggle for words, the failed attempts to find ways to describe the enormity of their frustration. Facing these checkpoints, one 
cannot formulate any coherent critique (except, obviously, for the significant critique of their mere presence), and one cannot ask, say, or demand anything, since all concrete demands have seemingly been attended to and the horror is still there, and since there is no one to talk to. At the new checkpoints one cannot see the soldiers or talk to them. The soldiers control the terminal from a sealed construct behind bulletproof and soundproof glass. The glass is so impenetrable that even if one tries to get the soldiers' attention in light of a specific problem by knocking on it, one's fists make no sound.

Muteness is perhaps what happens to humanitarian organizations when they are digested by the powers they oppose. However, while all resistance to dominant power structures faces the risk of being absorbed into those structures (Foucault 1980; Brown 1995), there are additional factors that make this absorption even more rapid and deleterious in the case of CPW. The first is sociological in nature. It relates to the makeup and structure of the organization, which should be understood in relation to the two main aspects of the multifaceted structural racism in Israel, operating both on the Jewish-Palestinian axis and inside the Jewish population, between the "white" Ashkenazi Jews (of European descent) and the "black" Mizrachi Jews (of North African or Middle Eastern descent). The majority of the women in CPW are middle- to upper-class Jewish Ashkenazi women who belong to the heart of the Israeli establishment, the dominating political, cultural, and intellectual elite in Israel. ${ }^{12}$ Thus, the co-optation of the organization by the ruling powers should not take us by surprise. The fact that most CPW women are part of-and perhaps more significantly, are perceived as belonging to-the elite, increases the accessibility and therefore the likelihood of modes of operation that are based on cooperation. In the name of efficacy, CPW implicitly relies on the privileged social positioning of its members to gain access to high-ranking officers, parliament members, and the media, thereby facilitating co-optation by the dominant powers of the occupation.

This sociological factor has been analyzed at length in relation to antioccupation movements in Israel (Dahan-Kalev 1997; Helman 1999); we would therefore like to introduce a factor of a different order. It is possible that the easy, almost immediate transition from opposition to power to techniques of power in the case of CPW is rooted in a double symmetry that is formed between CPW and the army. The first symmetry is a derivative of an equivalent relation of the army (and more generally, dom-

\footnotetext{
12 This makeup is not unique to CPW. Most Israeli peace movements are composed, to a large extent, of middle-class Ashkenazi Jews (Helman 1999).
} 
inant Israeli discourses) and CPW (inasmuch as it is a humanitarian organization) to the Palestinians. ${ }^{13}$ Both relate to the Palestinians as possessing some form of excessive corporeality, in which one axis of corporeality overshadows all other axes of existence. Both hold opposite yet structurally identical perspectives in which the Palestinian is reduced to either a suffering or an explosive body. Giorgio Agamben makes a similar argument, claiming that both sovereign power and humanitarian NGOs relate to bare life, "and therefore, despite themselves, [humanitarian organizations] maintain a secret solidarity with the very powers they ought to fight" (Agamben 1998, 133). Yet while for Agamben bare life is life excluded from politics (an exclusion that constitutes this life as bare and delineates the political sphere), the lives that the activists of CPW attend to at the checkpoint are saturated with politics; their existence is almost overdetermined by the political situation of the occupation. It would probably also be imprecise to state that both perspectives objectify Palestinians, since suffering is not an attribute of objects. A more accurate account might suggest that both reduce Palestinian lives to rudimentary lives-lives that are uncannily dominated by one single mode of existence.

This symmetry to which the Palestinian body serves as a hinge, bearing the two opposite facets of suffering-both enduring and inducing itdoes not exhaust the parallels between the army and CPW. If we shift our gaze to the interplay between the bodies of the Palestinians and those of the other permanent inhabitants of the checkpoints, the soldiers, a second type of symmetry between the standpoints of CPW and the army reveals itself. Both see one type of bodies as intrinsically violent and the other type as innately vulnerable. While the army relates to all Palestinians as (potential) suicide bombers and to the soldiers as their designated victims, CPW sees all soldiers as carriers of uncontrollable violence and all Palestinians as jeopardized by this violence, if not as its actual victims. Since both operate within a matrix characterized by a deleterious friction between two types of excessive bodies, that of the Palestinian and that of the soldier, the perspectives of both CPW and the army resonate and therefore lead, intentionally or not, to a solution that maximizes the isolation of these two bodies - the Palestinian's and the soldier's—and both lead to the entrenchment of the checkpoints.

Between these two pivots of structural parallelism, the ground is set for a disturbing resemblance between the army and CPW, a resemblance

\footnotetext{
${ }^{13}$ In all other aspects of its activity CPW does not relate to the Palestinians in forms that produce this reductive effect; quite the contrary-as suggested above-it even aims to counter any attempts of the security forces and the mainstream Israeli discourses to do so.
} 
that produces another form of corporeal excess: the superfluous materiality of the checkpoints. It is this correspondence that enables the army to be attuned to the demands of CPW, granting it the veneer of sensibility to humanitarian consideration and bestowing upon it a cloak of legitimacy, thereby making the new terminals a troublesome product of a treacherous alliance and locating CPW always on the threshold of an abyss, always on the verge of operating against itself.

\section{Mothers, mistresses, and whores: Bodies of CPW activists}

An old man of about eighty, clutching a cane and leaning on his daughter, walked slowly across the checkpoint. The old man . . . got into the car lane and almost reached the other side of the checkpoint when the checkpoint commander appeared in front of him and ordered him to go back ... [ [and] stand in the lengthening queue like everyone else. I found it difficult to watch. It was simply mean. The man could hardly move. The commander, who could have used his discretion, checked his ID card and let him through, didn't bother to do it. It's not just that I couldn't watch; I couldn't keep quiet either-I went to the commander . . . and called at him: "Look into my eyes, would you let your grandfather walk such a distance?" However, the commander turned his back and snickered. I didn't let him off: . . . "Would you let your grandfather walk like that?" And he snickered. . . . Why should he worry-after all it's not his grandfather. It's only a Palestinian grandfather!

- CPW report, Huwwara, January 23, 2006 (translation ours) ${ }^{14}$

It seems that the fact that CPW is an all-women organization is but another instance of the recent years' trend toward the feminization of Israeli peace NGOs (Isachar 2003; Powers 2006). This feminization is by no means homogenous: the feminist and women-oriented organizations vary, even confront each other on many levels, especially regarding the specific meanings and implications of gender in their ideology and praxis. ${ }^{15}$ However, we would like to argue that despite significant differences between them, there is a single thread of reasoning that might be found in all the Israeli

${ }^{14}$ See http://www.machsomwatch.org/reports/viewReport.asp? step = 3\&reportId = $14060 \&$ link $=$ viewReport\&lang $=$ heb.

${ }^{15}$ Some of these organizations include only women (Bat-Shalom) or are defined as women-oriented organizations (Shuvi). Others, such as New Profile, rely on feminist frameworks. Some, like Four Mothers, rely on traditional gender roles; other organizations, on radical feminist grounds (Women in Black) and even queer theory (Black Laundry). 
women's peace movements: the fundamental perspective that assumes that the othering of women is a potential source of alternative politics. Most of these organizations share the view that gender is the key to understanding and approaching political circumstances and point to the nexus between the cultivation of heightened masculinity and the militarism of Israeli society.

Analyzing modes of operation, as well as declarative statements made by leading voices in CPW, reveals a different image. While CPW is allfemale in its constitution, it nevertheless diverges radically from the common form of gendered politics of most Israeli NGOs. Gender functions in CPW mainly as a tool. The all-female makeup of the organization is utilized to enable forms of activities that would not be tolerated or even feasible otherwise. According to statements made by Yehudit Keshet, one of the three founding members of CPW, and by the organization's former spokesperson, Adi Dagan, the women of CPW believe that including men might jeopardize the delicate interactions with the soldiers at the checkpoints and thereby endanger the type of activism CPW performs. This viewpoint assumes that women may find it easier to avoid one of the two extreme stances while facing the soldiers: either totally identifying with them or aggressively conflicting with them (Deutsch-Nadir 2005, 48; Keshet 2006, 35).

Reasoning that women are more equipped to maintain this balance may be debatable, and experience has shown that the organization has found itself dealing with women who occupied attitudes on these two extremes of the spectrum. ${ }^{16}$ Still, this line of reasoning reveals that the determining factor in the decision to restrict its membership to women only was that this makeup would enable the organization to sustain the form of activity its members consider desirable and effective. Furthermore, this reasoning rests on more fundamental grounds that are not openly acknowledged in statements made by CPW members: the conditions of possibility of CPW rely upon its all-female composition. The mere presence of a highly controversial political organization that is considered pro-Palestinian by the Israeli mainstream on the new front line of the

${ }^{16}$ Two cases might elucidate this claim. In the first, one of the activists physically attacked a soldier and in the second an active member volunteered to serve in reserve duty at the checkpoints. These uncharacteristic instances of confrontation and identification aroused fierce debates within the organization as to how it may prevent such cases from reoccurring. The intensity of these debates attests to the importance the members of CPW place on keeping a delicate balance when interacting with the soldiers for the integrity and the survival of the organization. 
army-controlled checkpoints is tolerable only because of the sexist presuppositions projected onto the activists.

These sexist presuppositions, which are common to many other societies, especially nationalistic and militaristic ones, place women in an external position vis-à-vis the political domain. Women in Israel are considered to be lesser political beings to men; their status as political actors within the discourse of national security is that of caregivers and family agents. Accordingly, the public ear is attuned to political statements that they make in their capacity as mothers and wives (Yuval-Davis 1989; Berkovitch 1999). ${ }^{17}$ The women of CPW utilize these preconceptions in order to position themselves, discursively and physically, at the nucleus of political dispute; it is exactly these biases that allow their access to the checkpoints. Nonetheless, once they are there, the type of activities the activists perform clearly deviates from their predetermined womanly roles. They do not position themselves as the carriers of peace values but instead operate on a different ground and from a different basis of legitimacy.

The activity of CPW amounts to a persistent attempt to undercut the man-war/woman-peace division that prevails not just under patriarchal conceptions but in many feminist analyses as well (Ruddick 1992). The women of $\mathrm{CPW}$ go out to the confrontational zones and directly intervene in army matters. Often it seems as though CPW activists almost compete with the army over the management of war at the checkpoints. They claim to know the rules, sometimes even better than the soldiers, gaining their authority from their regular and persistent presence at the checkpoints, which most often exceeds that of the soldiers. It is therefore common for CPW activists to confront soldiers, using statements such as "I have been standing at this checkpoint for over a year, you just arrived a few weeks ago; I can tell you that Red Cross vehicles can pass without needing special permits" or "I can tell you that you cannot detain a person just to teach him a lesson." They have access to high-ranking officers, access that most often the soldiers at the checkpoints do not have, access that gives them the opportunity to question specific commands and local decision-making processes. Thus it is not rare for a woman from CPW to demand the brigade commander's intervention in cases where a checkpoint commander seems to be incompetent, violent, or incapable of restraining vi-

17 This claim might seem odd considering the fact that mandatory military service in Israel applies to women as well as men. However, as the social benefits attained by the military service apply only to men, in the political sphere women are desoldierized (Izraeli 1997). 
olent soldiers. As we suggest elsewhere (Kotef and Amir 2007), by positioning themselves on the same ground as the military officers and questioning security forces' assertions of privileged access to knowledge, the women of CPW perform a praxis of delegitimization, undermining the very authority of the Israeli rule at the checkpoints.

Still, gender cannot be tamed and restricted to specific and prescribed functions; gender emerges and reemerges in uncalculated forms and unpredictable domains. In the case of CPW, it materializes as an engendered bodily excess of the activists, a bodily excess consolidated through stereotypical gender positions. ${ }^{18}$ The most common among these positions is a motherly position toward the soldiers. For some activists this position may be readily accessible, since many of them are indeed mothers and grandmothers of soldiers and most are of that age. More generally, it is a position that may be assumed as a tactical move aiming to constitute a stance from which their message can be heard. The activist consents to place herself in an acceptable and conformist womanly role, assuming that from it she may express highly controversial views regarding IsraeliPalestinian relations and intervene effectively. The motherly stance is most often prompted by a sense of urgency posed by concrete distresses and includes performing as a family agent, an educator, the one who reduces the levels of tension, or any combination thereof. As the family agent, the activist attempts to remind the soldier of his familial context and juxtapose it with the Palestinians' ("would you tolerate the same behavior toward your own grandfather?"). As educators, the activists conduct conversations with soldiers in which "the mother" tries to explain to the soldier why his conduct is unacceptable and that he should "behave." Attempts to calm the soldiers are usually not performed as direct interventions and are more part of the rationale of the all-female presence at the checkpoints-as mentioned above, the decision to make CPW an exclusively women's organization is rooted in the assumption that such a presence will lower the tension at the checkpoints.

More often than not, it is by these acts through which the mother position is assumed that the intervention of CPW at the checkpoint becomes effective. Consequently, when facing a sense of urgency, a form of activism that aims to undermine gender stereotypes and conservative gender-based political divisions eventually materializes in forms that intensify and reify the same stereotypes and divisions. Still, perhaps this account of the double-edged nature of activism is too clean in its attempt to sustain

${ }^{18}$ For an additional analysis of gendered bodies in the Israeli Left movement opposing the occupation, see Sasson-Levy and Rapoport (2003). 
a dichotomy between subverting gender roles and reproducing them. As with any performance of any identity, gendered or otherwise (Butler 1999), by performing motherhood at the checkpoint CPW women do not simply reproduce and reinforce a traditional prescribed role. Mothers, as a normative and regulatory ideal, care; they feed, they spoil their children. Checkpoint Watch women do not. It is thus a very common occurrence that the soldiers react angrily to this perceived failure and blame the CPW activists for neglecting to bring cookies or soft drinks for them. The "failure" to perform motherly care is rooted in a more critical failure: the main care and concern is not aimed toward members inside "the family" of Jewish-Israelis, and specifically the soldiers, but rather toward the Palestinians. Indeed, examining the explicitly gendered activities performed by the CPW women in the context of their identities as mothers clearly shows a sharp division in the allocation of the resources that this role possesses. While practices of education, appeasing, and making present the familial context are directed toward the soldiers, care and concern are expressed toward the Palestinians. This split may be read as performing a subversive implementation of this gendered position, making use of a prescribed identity that the CPW activists cannot completely avoid. This is particularly true in the Israeli context, in which reproduction is interwoven into racial divisions and constructed as a barrier whose aim is to foreclose the boundaries of race (Melamed 2004).

However, this analysis assumes that occupying one's identity is fully in one's possession and may be activated according to one's will. As Butler (1999) claims, identities in general and gender identities in particular cannot be inhabited in a stable and foreclosing manner; the inherent instability of gendered positions dictates the need to constantly reoccupy them anew, to reperform them in order to inhabit them. Thus, since these positions are never mere tools that are fully controlled by the individual, the meanings and implications derived from these positions are also available for misreadings and appropriation by others. Indeed, such misreadings of the positions of CPW women as mothers often occur at the checkpoints. These readings project onto the activists the Jewish-Israeli normative role of the mother-of-the-soldier in its coherent form, erasing the split between the addressees of the motherly attention mentioned above. The surprise and resentment expressed by the soldiers when CPW women fail to provide the expected care and concern toward them is one example among many. Similarly, parents of soldiers sometimes address the activists and seek their help in caring for the soldiers at the checkpoints.

This analysis may aid in understanding some of the more complex implications of the presence of the CPW activists at the checkpoints. Is 
it possible that these calls, which interpellate the CPW women as mothers even in terrains they aim to leave clean of motherly traces, carry implications beyond the realm of gender? Is it possible that in their presence at the checkpoints as mothers CPW women have turned the checkpoints into one of the sites in which the army is exposed to parental supervision, one of the sites in which parental inspection necessitates paying more attention to the "working conditions" of soldiers?" ${ }^{19}$ And is it possible, then, that this supervision-which is never taken on by CPW women as one of their roles but is nonetheless an outcome of their collapse into motherhood-contributed to the form the new terminals took $?^{20}$ Can it be that the role CPW played in the entrenchment of the checkpoints is a function not only of the group's humanitarian interventions but also of the gendered attribute of these interventions? Whatever the answers may be, being a mother at the checkpoint is not a position one can simply jump into and out of as one pleases. And yet, being a mother at the checkpoint-and more generally, assuming gendered positions-is not something CPW women can elude. This is not only because the gender role is projected onto them but also because it facilitates a trade-off in which more conservative gender politics allows a radical form of activism to sustain itself.

This trade-off is even more apparent in another gendered and highly embodied figure through which some CPW women operate at the checkpoints: that of the sexualized body. In this domain there are two main positions: that of the sexual object and that which is banished out of the legitimate domains of (racist-delineated) sexuality to the deviate zones of perversion: "the Arabs' whore." Appropriating the role of a sexual object, much like appropriating that of the mother, is a modus operandi at the checkpoint. Though not commonly used, this position often proves to be the most effective. The CPW woman offers the soldier bits of flirtatious attention, which usually takes place in the form of a bargain: she gives him some affection and lets him see her as a sexual being, and he in return performs as a "better person," giving her more considerate treatment of

19 On parental involvement in the Israeli army and its implications, see Herzog (2004).

${ }^{20}$ Unlike the older checkpoints, the new terminals are designed to provide maximal protection to the soldiers. One may therefore argue that when the terminals were designed, parental considerations regarding the well-being of the soldiers at the checkpoints gave this issue precedence. 
the Palestinians. ${ }^{21}$ This technique achieves effects that no other technique can. To tell one story among many, one of us stood at the Beit Iba checkpoint in January 2005. The lines were unbearably long: people had been standing in them for hours and hours, squeezed almost to the point of not breathing, while the sound of crying babies filled the air. The horrendous pressure was magnified by the malicious conduct of the soldiers, who worked spitefully slowly and completely stopped letting people through every few minutes. A group of officers stopped by. We tried everything we could to make them use their authority and additional personnel to improve the situation; they kept insisting that this was not their job and was none of their business. One of us then started flirting with one of them. In a short while he entered the checkpoint and started checking and letting Palestinians through. The line of people was dramatically reduced in minutes. On releasing a group of men who had been delayed on their way to Nablus, he approached the CPW member, his right hand on his heart, and bowed. "I released them for you," his body language stated.

It is important to ask what happens in these situations, what is produced and ratified, what is contested, and what effects are achieved. This technique duplicates a traditional man-woman relationship in which she offers him sex and he offers her his assets, material and otherwise. The only difference here is that instead of economic benefits, the woman receives the well-being of the Palestinians. Hence, the sexuality of the woman is objectified in an almost commercial transaction. But are other effects produced along the way? Perhaps the fact that this objectification is not a collapse into an assigned position but is instead utilized in order to gain more control over the situation suggests that there is more agency involved. But is this utilization of sexuality not just another case of the prevalent (hetero)sexual game? Moreover, do we find more agency and more subversiveness here than in many other situations? Is not gender itself constituted from these building blocks (Butler 1999)? And perhaps more important, are these the questions we have to ask when dealing with the checkpoints? It is more important to note that this technique objectifies not just the activist but also the Palestinians. It reproduces not just the reification of the activist, making her sexuality a commodity, perhaps

${ }^{21}$ Although at some of the checkpoints there are female soldiers, the checkpoints are overwhelmingly manned by male soldiers, and the checkpoint commander is almost always a male. Therefore the interaction between the soldiers and the CPW women is conducted along the lines of a heterogendered dichotomy. 
her most valuable commodity; it also reproduces the dehumanization of the Palestinians: they are the property of the soldier to give. Then again, perhaps the only thing that matters here is the effectiveness, the fact that some-sometimes many-people get to go home, to work, to their families with fewer delays or without having to endure the soldiers' violent outbursts.

This measure of effectiveness, assessed by the degree to which the immediate toll of the checkpoints on the lives of the Palestinians is alleviated, is not shared by all CPW members. One of the stances adopted by some of the activists is rooted in the belief that any form of cooperation with the ruling authorities is necessarily flawed and should be avoided at all cost. These women adopt a confrontational stance toward the soldiers; they argue with them fiercely and try to sabotage their ability to manage and control the checkpoints efficiently. They also refuse to align themselves to the gendered positions described above. However, every so often, these women are reminded that falling into traditional gender roles is never completely avoidable. In the eyes of the soldiers, they become Arabs' whores, a common curse in Jewish-Israeli society that is usually hurled at female-left activists or ideologists. This identity claim underscores the manner in which race and sexuality are interlaced in the Jewish-Israeli nationalistic discourse, to the extent that what is regarded as transgression on the axis of nationalism and race is cast as what is perceived as sexual perversion.

In fact, it would be more accurate to speak here not of different types or groups of women but of different strategies, occasions, and incidences in which different women take on this or that role. It is rare to find CPW women who can successfully maintain the same position or those who intentionally aim to make use of a single, stable, and constant strategy. One occurrence that clearly illustrates this point happened to one of the most radical CPW women. Although she consistently endorsed an adversarial attitude toward the soldiers, she discovered that a high-ranking officer had taken a liking to her. Although she was not willing under any circumstances to change her attitude toward him, he claimed that he was willing to do anything as long as she was willing to talk to him. Gradually, she started turning and asking for his help whenever she encountered severe and violent incidents at the checkpoints, despite her strong convictions opposing any cooperation with the army, and reluctantly occupied the role of the flirtatious woman in essence if not in form.

One can claim that the formation of bodily excess in the case of CPW women not only derives but also deviates from the two types of bodily excess with which we began our article, that of one single axis of cor- 
poreality gaining dominance over all others and that of contextual diversion from a given norm. First, since the forms of activity we have just outlined by no means diminish all other actions of CPW activists, the bodily axes they produce do not dominate the women's corporeal presence. In other words, CPW women are not present at the checkpoint first and foremost as mothers, mistresses, or whores, but as political activists. And yet, because the presence of the activists at the checkpoint is always in jeopardy, negotiable, and in need of reestablishment, when these corporeal axes appear, they always threaten to become the sole logic of this presence. Second, these appearances do not transgress the norm (as much as heteronormativity can be thought of in the singular form): reproduction and sexuality are clearly part of the normative construction of femaleness. Nonetheless, at the checkpoint reproduction and sexuality appear out of place: on the front line rather than at home. Perhaps more important, they exceed and transgress the organization's imaginary self; they radically diverge from the manner in which CPW sees itself and its activity. Therefore, at the checkpoint, these appearances constitute a bodily excess. It may then be stated that the bodies of CPW women participate in an intricate game of give-and-take in which gender functions on multiple plateaus. Gender provides access to the checkpoints, facilitates certain forms of activism, and amplifies the effectiveness of some while undoing others.

\section{Conclusion}

In this article we explored ways in which political activism works in spite of itself. We aimed to mark a trail through which this self-impediment might be understood, a trail traversing through gender. This trail began with the way gender functions in the conditions of the occupation itself. We showed how the Palestinians' occupied bodies are carved into a gender binary, wherein one side links suffering and femaleness (in the figure of the woman giving birth at the checkpoint) and the other fuses masculinity and violence (in the figure of the suicide bomber). We showed how this male/female binary, which usually serves to preserve gender orders, operates to sustain a different type of order-that of the occupation. Although CPW operates to bring about the termination of the checkpoints, its modus operandi also challenges, on many levels, both the above-mentioned gender division and the positions assigned to women in Israeli society.

However, the activities performed by CPW members include elements that repeatedly disrupt the organization's own objectives on these two 
fronts. Facing massive injustice at the checkpoints, an almost uncontrollable urge to act effectively arises. Since the ability to alleviate the suffering at the checkpoints demands the soldiers' cooperation, and since the checkpoints are highly gendered military zones, attempting to be effective sometimes results in the activists finding themselves reassigned to traditional and even stereotypical gender roles. Gender overflow is not the sole cause for the organization's digression from its course; the humanitarian impulse to alleviate suffering contributes to this process as well. As the object of this impulse is many times a body that is reduced to one axis of corporeal existence, it resonates with the army's construction of Palestinians as explosive bodies. And as the perspectives both of CPW and of the army position this object in a dyad wherein there is friction between vulnerable and violent bodies that necessitates separation by walls, this resonance results in the ever-progressing material excessiveness of the checkpoints.

Nonetheless, the implications of CPW extend beyond those explored in this article. Before the activity of the organization gained momentum, the reality of the checkpoints-a major aspect of the Israeli rule in the Occupied Territories that has devastating effects on every facet of Palestinian life-was generally overlooked. Not only were the fragmentation of the West Bank, the constant siege, the routine of daily humiliation, incidences of violence, and arbitrary bureaucratic hardship outside the scope of public debates internationally and in Israel, but the mere existence of the checkpoints was also largely unrecognized. The activity of the organization was, and still is, one of the most significant contributors to the effort of bringing the checkpoints into Israeli and international focus. It also manages to affect the manner in which the checkpoints themselves operate in crucial ways that this article did not cover and to diminish in various aspects some of their harmful implications. Though reality produces incalculable effects that might undermine the goals of the organization, and though conceptual frameworks sometime consolidate into concrete apparatuses that prompt a sense of muteness and paralysis, this article is in no way a call for nonaction or political disengagement. Facing the checkpoints, facing catastrophe in the making, neither acting against the occupation nor analyzing the consequences of such interventions can be relinquished.

School of Philosophy

Tel Aviv University (Kotef)

The Cohn Institute

Tel Aviv University (Amir) 


\section{References}

Agamben, Giorgio. 1998. Homo Sacer: Sovereign Power and Bare Life. Trans. Daniel Heller-Roazen. Stanford, CA: Stanford University Press.

Amnesty International. 2005. "Israel Ve-Hashtachim Ha-Kvushim Conflict, Kibush Ve-Patriarchaliyut: Nashim Nos' ot Ba-Netel" [Conflict, occupation, and patriarchy: Women carry the burden]. Report. AI Index: MDE 15/016/2005 http://amnesty.org.il/israel/women042005.doc (in Hebrew).

Azoulay, Ariella, and Adi Ophir. 2004. "The Ruling Apparatus of Control in the Occupied Territories." Paper presented at the Van Leer Jerusalem Institutethe Politics of Humanitarianism in the Occupied Palestinian Territories, Jerusalem, April 20.

Berkovitch, Nitza. 1999. From Motherhood to Citizenship: Women's Rights and International Organizations. Baltimore: Johns Hopkins University Press.

Brown, Wendy. 1995. States of Injury: Power and Freedom in Late Modernity. Princeton, NJ: Princeton University Press.

Butler, Judith. 1999. Gender Trouble: Feminism and the Subversion of Identity. New York: Routledge.

- 2004. Precarious Life: The Powers of Mourning and Violence. London: Verso.

Dahan-Kalev, Henriette. 1997. "The Oppression of Women by Other Women: Relations and Struggle between Mizrahi and Ashkenazi Women in Israel." Israel Social Science Research 12(1):31-44.

Deutsch-Nadir, Sharon. 2005. “Capitalizing on Women's Traditional Roles in Israeli Peace Activism: A Comparison between Women in Black and Checkpoint Watch." Masters thesis, Tufts University.

De Waal, Alex. 1997. Famine Crimes: Politics and the Disaster Relief Industry in Africa. Bloomington: Indiana University Press.

Fanon, Frantz. 1967. Black Skin, White Masks. Trans. Charles Lam Markmann. New York: Grove.

Foucault, Michel. 1980. "Power and Strategies." In his Power/Knowledge: Selected Interviews and Other Writings, 1972-1977, 134-45. New York: Pantheon.

Hammami, Rema. 2000. "Palestinian NGOs since Oslo: From NGO Politics to Social Movements?" Middle East Report 214 (Spring): 16-19, 27.

Hass, Amira. 2006. "Israeli Restrictions Create Isolated Enclaves in West Bank." Ha'aretz, March 24, 1, 3. Available at http://www.kibush.co.il/show_file.asp ?num $=12852$.

Helman, Sara. 1999. "From Soldiering and Motherhood to Citizenship: A Study of Four Israeli Peace Protest Movements." Social Politics: International Studies in Gender, State and Society 6(3):292-313.

Herzog, Hanna. 2004. "Family-Military Relations in Israel as a Genderizing Social Mechanism." Armed Forces and Society 31(1):5-30.

Isachar, Hedva. 2003. Achayot Le-Shalom: Kolot Ba-Smol Ha-Feministi [Sisters in peace: Feminist voices of the left]. Tel Aviv: Resling. 
Izraeli, Dafna N. 1997. "Gendering Military Service in the Israeli Defense Forces." Israel Social Science Research 12(1):129-66.

Keshet, Yehudit Kirstein. 2006. Checkpoint Watch: Testimonies from Occupied Palestine. New York: Zed.

Kotef, Hager, and Merav Amir. 2007. "On Imaginary Lines; Biopolitics, Disciplinary Apparati and Sovereign Violence at the Checkpoints.” Paper presented at the annual meeting of the Association of American Geographers, San Francisco, April 17-21.

McClintock, Anne. 1995. Imperial Leather: Race, Gender, and Sexuality in the Colonial Context. New York: Routledge.

Melamed, Shoham. 2004. "Motherhood, Fertility, and the Construction of the 'Demographic Threat' in the Marital Age Law." Theory and Criticism 25 (Fall): 69-96.

Naaman, Dorit. 2007. "Brides of Palestine/Angels of Death: Media, Gender, and Performance in the Case of the Palestinian Female Suicide Bombers."Sians: Iournal of Women in Culture and Society 32(4):933-55.

Powers, Janet M. 2006. Blossoms on the Olive Tree: Israeli and Palestinian Women Working for Peace. Westport, CT: Praeger.

Prendergast, John. 1996. Frontline Diplomacy: Humanitarian Aid and Conflict in Africa. Boulder, CO: Lynne Rienner.

Ruddick, Sara. 1992. "Preservative Love and Military Destruction: Some Reflections on Mothering and Peace." In Feminisms: A Reader, ed. Maggie Humm, 298-303. New York: Harvester Wheatsheaf.

Sasson-Levy, Orna, and Tamar Rapoport. 2003. "Body, Gender, and Knowledge in Protest Movements: The Israeli Case." Gender and Society 17(3):379-403.

UN Office for the Coordination of Humanitarian Affairs. 2006. West Bank Closure Count and Analysis, January 2006. New York: United Nations.

Yuval-Davis, Nira. 1989. "National Reproduction and 'the Demographic Race' in Israel." In Woman, Nation, State, ed. Nira Yuval-Davis and Floya Anthias, 92-109. Houndmills, UK: Macmillan.

Zeedani, Said. 2005. "A Palestinian Perspective on the Checkpoints." Occupation Magazine: Life under Occupation, September 29. http://www.kibush.co.il/ show_file.asp? num $=9277$. 